\title{
Imaginarios de corrupción en Perder es cuestión de método, de Santiago Gamboa*
}

Fecha de recepción: 25 de junio de 2017

Fecha de aprobación: 12 de septiembre de 2017

\section{Resumen}

El artículo responde a la pregunta sobre el sentido de los imaginarios de corrupción en la novela Perder es cuestión de método (1997) de Santiago Gamboa. Para responder a esto, el imaginario se presenta como un ensamblaje relacional de imágenes dilemáticas, mientras que la corrupción se define, desde el contenido de la obra, como una acción ilegal y egocéntrica que sitúa el interés propio por encima de los intereses de la mayoría política. Con el análisis semiótico de enunciados y de figuras se llega a determinar, cómo están figurados los imaginarios de corrupción en la novela de Gamboa y se categorizan según el estrato en que esta se manifiesta, a saber: fisiológico, psicológico y social. Igualmente, se focaliza el análisis de la figura del empalado en la que dichos planos se determinan recíprocamente y que da organicidad al tema que desarrolla la narración.

Palabras clave: Enunciación. Imaginarios. Corrupción. Novela colombiana. Santiago Gamboa.
Citar: Avilés Arenas, L. (julio-diciembre de 2017). Imaginarios de corrupción en Perder es cuestión de método, de Santiago Gamboa. La Palabra, (31), 177-190. doi: https://doi.org/10.19053/01218530.n31.2017.7275.

\section{Leonor Avilés Arenas}

Docente e investigadora de la Universidad Industrial de Santander. Magíster a en Semiótica de la Universidad Industrial de Santander. Magíster en Formación de Profesores de Español como Lengua Extranjera, Universidad de León.

leoavilesar@gmail.com

* Artículo de reflexión, resultado de una investigación sobre las imágenes e imaginarios de corrupción en las novelas Perder es cuestión de método (1997), de Santiago Gamboa, Paraíso Travel (2001), de Jorge Franco y Satanás (2002), de Mario Mendoza y en las versiones cinematográficas homónimas dirigidas, respectivamente, por Sergio Cabrera, Andy Baíz y Simón Brand. En estas obras, que corresponden al periodo de producción de la novela policíaca o negra colombiana contemporánea (siglo XXI), se relacionan diversos hechos de corrupción y la pesquisa se interesa, en esencia, en la descripción científica de la coherencia entre las figuraciones narradas con el lenguaje literario y luego traducidas al lenguaje fílmico La investigación se ha desarrollado en el Centro de Investigaciones CAER, Centre Aixois d'Études Romanes, Aix-Marseille Université (Francia), con la participación del grupo de investigación Cultura y Narración en Colombia (Cuynaco), de la Universidad Industrial de Santander en el periodo 2012-2016. 


\title{
la palabra
}

\section{Imaginaries of corruption in Perder es cuestión de método [Losing is a Matter of Method] by Santiago Gamboa}

\begin{abstract}
The article interrogates the meaning of imaginaries of corruption in the novel Perder es cuestión de método (1997) by Santiago Gamboa. For this, the imaginary is understood as a relational assembly of dilemmatic images; while corruption is defined, based on the content of the work, as an illegal and egocentric action that places self-interest above the interests of the political majority. The semiotic analysis of statements and figures will be used to determine how imaginaries of corruption are represented in Gamboa's novel. These imaginaries are classified according to the stratum in which they manifest themselves: physiological, psychological and social. The analysis also focuses on the fact that these strata are interdependent and work as parts of a complex phenomenon; contributing to the organicity of the narrative.
\end{abstract}

Key words: enunciation; imaginary; corruption; Colombian novel; Santiago Gamboa.

\section{Les imaginaires de la corruption dans Perder es cuestión de método [Perdre est une question de méthode] de Santiago Gamboa.}

Dans cet article nous nous interrogeons sur le sens des imaginaires de la corruption dans le roman Perdre est une question de méthode (1997) de Santiago Gamboa. L'imaginaire serait un assemblage qui met en rapport des images dilemmatiques tandis que la corruption se définirait, d'après le roman, comme une action illégale et egocentrique qui place l'intérêt individuel par-dessus les intérêts d'une majorité politique. Á partir d'une analyse sémiotique des énoncés et des figures nous déterminerons de quelle manière sont construits les imaginaires de corruption dans le roman de Gamboa et nous catégoriserons dans quelle couche se manifestent-ils: physiologique, psychologique et sociale. Nous nous focaliserons sur l'analyse de la figure de l'empalé où tous les plans se déterminent de manière réciproque tout en donnant une dimension organique au sujet développé dans la narration.

Mots-clés: énoncé. imaginaires. corruption. roman colombien. Santiago Gamboa. 


\section{Presentación}

La complejidad del fenómeno de la corrupción, sus profundos vínculos con otros problemas socioeconómicos y políticos como el crimen organizado, la inequidad y la injusticia, han sido recreados de manera magistral en Perder es cuestión de método. También, la novela de Gamboa ${ }^{1}$ ilustra y particulariza el contexto sociocultural colombiano y la manera en que este flagelo ha proliferado en todas las esferas, en todos los sustratos de nuestra cotidianidad, y se expresa tanto en comportamientos ilegales que se legitiman.

El propósito fundamental de este artículo es delimitar una noción de imaginarios de corrupción que permita examinar los enunciados sobre las figuras más significativas de este asunto en la novela de Gamboa. Para ello, se examinarán algunos apartados de Perder es cuestión de método para establecer cuáles son los enunciados ${ }^{2}$ en los que los imaginarios de corrupción se reconfiguran en esta obra narrativa, cuáles serían los significados contenidos en estas construcciones figurativas más relevantes, y de qué modo algunos planos de imaginarios de corrupción se condesan en dichas figuras.

\section{Imaginarios}

Landowski (2013) plantea que, a pesar la vaguedad en el tratamiento teórico del término imaginario, es posible proponer una dialéctica entre dos facetas complementarias, aunque conflictivas, de la noción de imaginario: una corresponde a la imaginación y la otra al poder de creación. Así pues, el imaginario designa claramente, a la vez, una cosa y su opuesto; es decir, sería un conjunto de imágenes (lo imaginado), representaciones o figuras fijas que, a la vez que una potencia (imaginante), opera como un proceso creador de imágenes. Además, el mismo autor explicita que el interés por el imaginario implica observar las relaciones internas que unen la racionalidad y la irracionalidad de las construcciones del espíritu, y por la manera como esas relaciones toman senti- do por sí mismas (2013). Esto quiere decir que, a pesar de lo abstracto de la noción, es posible extraer principios de organización del pensamiento que hacen inteligible la manera como una colectividad conceptualiza y reconfigura su propia existencia y su relación con el mundo a través de elementos figurativos con que se manifiestan los contenidos (imaginarios) en diversas prácticas significantes.

Anne Sauvageot (2004) propone el imaginario como el conjunto de todas las imágenes posibles, tanto pasadas como presentes o futuras, sobre un asunto tratado discursivamente. Este imaginario cubriría también aquellos procesos dinámicos a través de los cuales esas imágenes son producidas, almacenadas y transformadas en el pensamiento. Además, sostiene que todo imaginario es tanto singular como colectivo, individual y, al tiempo, determinado socialmente. De tal manera, los imaginarios pueden comprenderse como el conjunto de imágenes mentales acumuladas por el individuo a lo largo de la ex-

El presente artículo resulta de una investigación sobre las imágenes e imaginarios de corrupción en las novelas Perder es cuestión de método (1997), de Santiago Gamboa; Paraíso Travel (2001), de Jorge Franco; y Satanás (2002), de Mario Mendoza; y en las versiones cinematográficas homónimas dirigidas, respectivamente, por Sergio Cabrera, Andy Baíz y Simón Brand. En estas obras, que corresponden al periodo de producción de la novela policíaca o negra colombiana contemporánea (siglo XXI), se relacionan diversos hechos de corrupción y la pesquisa se interesa, en esencia, en la descripción científica de la coherencia entre las figuraciones narradas con el lenguaje literario y luego traducidas al lenguaje fílmico. La investigación se ha desarrollado en el Centro de Investigaciones CAER, Centre Aixois d'Études Romanes, Aix-Marseille Université (Francia), con la participación del grupo de investigación Cultura y Narración en Colombia (CuynaCo), de la Universidad Industrial de Santander en el periodo 2012-2016.

2 En términos de Panier (2003), un texto o un enunciado es un discurso producido y, en tanto que producto, presupone las condiciones de producción (o de comunicación). A nuestro juicio, estas condiciones de producción de la obra y las de interpretación (actualización de la novela por el lector) son escenas prácticas (Fontanille, 2008) que no son ajenas a la manera en que se construye el sentido de la obra, sea como objeto de fruición o de análisis científico. 
periencia de socialización en el seno de la comunidad cultural, lo que no hace difícil comprender que se trata del conjunto de imágenes e ideales de donde se nutre todo grupo social.

\section{Imaginarios de corrupción}

La noción de corrupción también posee una dinámica ambivalente como la del imaginario. Se define, desde lo socioeconómico, como la acción ilegal y egocéntrica que sitúa el interés propio (de un individuo o un grupo reducido) por encima de los intereses de la mayoría política y social, a la que se debe servir o con la que se tiene algún tipo de compromiso (Gallón Gómez y Gómez Portilla, 2000). La acción del corrupto, aun en las esferas más íntimas, es caracterizada desde el horizonte axiológico de los universos sociolectales de las narraciones y afecta el patrimonio común e institucional o privado, pues según el impacto social del individuo que se corrompe y corrompe, los actos de corrupción adquieren una valoración negativa relevante a partir de la interacción y las dimensiones política y jurídica del entorno social. La aceptación de estos procedimientos deslegitima $\mathrm{y}$ vuelve ineficaces las acciones de los particulares y de las instituciones; además, las políticas públicas se pervierten, con lo que se acentúa la percepción de que los sujetos (tanto hacedores de la corrupción como las víctimas) viven en un ambiente de injusticia que alimenta a los mismos procesos de descomposición. En los contextos culturales como el colombiano, la corrupción sería un sustrato de memoria colectiva que, como un legado colonial (Fajardo, 2002), condena a los actores sociales a privilegiar valores, intereses y el bienestar de las minorías poderosas.

Los imaginarios de corrupción serían el conjunto de imágenes individuales y colectivas sobre los comportamientos y acciones ilegales que benefician a un individuo o un grupo, en detrimento de los intereses de otros. Para Deneault, el experto o competente puede convertirse en un mediocre, porque neutraliza el pensamiento crítico para satisfacer los intereses de aquellos que lo utilizan a cambio de paga; este modo de actuar, expresa, se convierte en el discurso político dominante, sin acciones divergentes, y conduce a los sujetos a ceder a las tentaciones de las ventajas en cualquier ámbito de la vida social (Deneault, 2015). Esto significa que los imaginarios de corrupción, además de ser sustrato del comportamiento delictivo, son figuras y representaciones que han encontrado recursos para legitimarse, al punto que ellas se podrían considerar como un comportamiento social ideal, a pesar de ir en contra de ciertos valores. Los actos de corrupción se emularían diariamente en todos los estratos del entorno sociocultural tras un aparente bienestar que se alcanza fácilmente. Los imaginarios de este tipo repercuten en la percepción distorsionada (desvaloración) de la justicia, la clase política dirigente y los recursos públicos, y de la percepción y autoestima de los sujetos.

\section{Metodología}

El análisis realizado está enmarcado en la semiótica de la cultura, dado que en ella se insertan los estudios de los imaginarios como procesos de representación y toma de decisiones. Para ello, se procede a la lectura de la obra (novela) en tres niveles de organización ${ }^{3}$; el primero corresponde al nivel figurativo, por medio del cual se accede a la reconstrucción de los procesos transformacionales que encarnan el sistema axiológico o nivel del contenido del objeto significante. El segundo nivel es el semio-narativo en el que se verifica la hipótesis sobre la secuencia narrativa. En el tercer nivel axiológico, se recuperan las conexiones de interdependencia entre figuras, acciones y valores, lo que es la

3 Para Panier (2003), los niveles son: a) El figurativo ¿cómo está enunciado?, b) el semio-narrativo ¿qué es lo que está enunciado? y b) axiológico ¿cuál es el contenido de lo relatado? 
descripción, con el metalenguaje, de las imágenes e imaginarios, en este caso, específicos de corrupción. Para esto, debe considerarse que una semiótica del imaginario da cuenta de las operaciones subyacentes que juegan con los motivos figurativos y de los espacios teóricos e ideales de un imaginario, lo que es, en suma, el espacio de las operaciones semióticas que condicionan la producción y la captación del sentido figurativo (Landowski, 2013) o de las imágenes que convergen en el imaginario.

Con respecto de las operaciones enunciativas en los objetos significantes, como la novela, Fontanille expresa que la instancia de enunciación es un actante de control que regula el qué, cómo y cuánto se predica para el destinatario (Fontanille, 2001), de tal suerte que la instancia enunciativa que predica en la novela es también un operador de manipulación que establece las coordenadas de la cooperación textual del lector sobre la base de la organización del enunciado. Esta manipulación discursiva, entendida como "la acción del hombre sobre los otros hombres" (Greimas y Courtés, 1991, p. 251), hace que los actantes del plano de la enunciación y los del plano del enunciado (lo narrado) ejecuten, cada uno, un programa dado que es realizable a partir del hacer-hacer (intervención), en el plano pragmático, o un hacer-creer (sumisión), en el plano cognoscitivo. Así, la novela es un dispositivo discursivo que, a través de la instancia de enunciación, manipula al lector cooperante (Eco, 1981), y manipula la organización del sistema de creencias en que se desenvuelven los actantes del relato.

La manipulación en la organización del discurso novelesco, hace que la instancia de enunciación, que se comporta como un sujeto que manipula, y que los sujetos del enunciado reportado por la enunciación (es decir, los sujetos del relato) produzcan una transformación en el estado modal del sujeto manipulado, convertido en un sujeto de hacer del programa que el manipulador quiere o necesita que sea ejecutado como propio o de otro sujeto (Serrano, 2003, p. 11). En este orden de ideas, el análisis de la novela Perder es cuestión de método navega por los niveles de análisis ya mencionados, con la intención de recuperar cómo aparecen las figuras e imágenes de corrupción que van a conducir, tanto a los sujetos del universo sociolectal contenido en la narración, como al enunciatario, a construir el imaginario de la corrupción con que, entre otros muchos elementos, esta narrativa específica alude al mundo social que retrata o representa.

Sobre los imaginarios de corrupción en Perder es cuestión de método

En la novela de Gamboa, el empalamiento de Casiodoro Pereira Antúnez es el detonador de la manera como se presenta la historia policíaca o novela negra (Pöppel, 2001). Ello suscita una serie de interrogantes, una serie de hechos delictivos y el seguimiento de las pistas sobre los móviles del crimen, en los cuales se involucra el periodista Silanpa y su ayudante Estupiñán; además, esta pesquisa se vincula con tres grupos de crimen organizado que se enfrentan con el fin usufructuar de los terrenos de Sisga, cuyo dueño era Pereira Antúnez. El sujeto enunciador del empalamiento es Vargas Vicuña, jefe de una de las organizaciones criminales, y quien con la complicidad ${ }^{4} \mathrm{del}$ Capitán Moya, logra quedarse con los terrenos de Sisga, como infiere el lector en las páginas finales de la novela: "el sotoscripto se inicia en algo nuevo,

\footnotetext{
$4 \quad$ El capitán Moya libera a Vargas Vicuña, Tiflis y Susan Caviedes, a pesar que Silanpa y Estupiñán le entregan pruebas de que son autores de la muerte de Pereira Antúnez y de Ósler Estupiñán. Por su encubrimiento, el capitán Moya obtiene un empleo luego de su jubilación. Este es un caso de tráfico de influencias, un delito directamente vinculado con la corrupción, que consiste en que se elige y se obtiene el beneficio para sí mismo como funcionario público, antes que favorecer o elegir la mejor oferta o al ciudadano que esté mejor calificado para un empleo u ofrezca mejores condiciones en un contrato (Piedrahita, 2012).
} 
a la cabeza de la seguridad de uno de los empresarios de más pujanza y valor de nuestra respetada nación: el constructor Ángel Vargas Vicuña" (Gamboa, 1997, p. 333).

El empalado, además de ser el cuerpo del delito y foco de la investigación asignada a Silanpa por el capitán Moya, se constituye en uno de las figuras más significativos de la novela: "Una vaina de esas no se hace sin odio, Víctor, y un odio muy profundo. Eso no es sólo un crimen. Ahí hay humillación, desprecio, bajeza" (Gamboa, 1997, p. 19). El sujeto enunciatario del empalamiento está conformado por las otras dos bandas criminales que se disputan las escrituras de los predios ${ }^{5}$ de Pereira Antúnez, como lo explicita Silanpa en el borrador de "Historia de un cadáver": "Entonces Vargas Vicuña ordenó clavar el cuerpo a la orilla del lago para meterle miedo a los de Hijos del Sol y mostrarle a Tiflis y a Esquilache quién era el más fuerte" (Gamboa, 1997, p. 260). ${ }^{6}$

En la enunciación como acto de la comunicación, continúa Courtés, enunciador y enunciatario tendrán a su vez los roles de sujetos de hacer y de sujetos de estado. Pero, puntualiza el autor, más que un saber hacer, la enunciación en la comunicación es más que todo hacer creer. $\mathrm{Si}$ se traslada esta dinámica a la relación comunicativa entre los actores del relato (colectivos o particulares) mediada por el mensaje constituido por el empalado, se observa que se entra en una dinámica de manipulación entre los operadores de la acción. Vargas Vicuña manipula por intimidación, al mostrar el cadáver de Pereira Antúnez empalado (mensaje manipulador), pues con esta violencia hace que los adversarios le teman. Esto le permite construir una imagen precisa en el universo sociolectal: se muestra como el más temerario frente a Tiflis, jefe y ex-esmeraldero; y frente a Esquilache, concejal corrupto que debe favores políticos al GranCapital. De este modo, en el pasaje enunciado en que se expone al empalado Pereira Antúnez y las consecuencias de esta figura aterradora (entre otras cosas, por la consunción de la víctima y la extrema violencia infligida a un congénere), va a converger en una serie de figuras que constituyen uno de los imaginarios de corrupción fundamentales de la novela de Gamboa.
Más interesante aún es que, en el desarrollo del conflicto narrado, esta figura escandalosa condensa diversos planos de manifestación de la corrupción al tiempo que las despliega, no solo por ser la figuración de un mensaje que entra en circulación entre los actores del relato, sino porque obra como disparador de otras acciones relacionadas con la corrupción. En este orden de ideas, la figura del empalado condensa varios planos o estratos de corrupción que se relacionan entre sí, al punto de determinarse recíprocamente, en el sentido en que cada plano implica al otro como causa, soporte o resultado. Estas manifestaciones de la corrupción serían fisiológica, psicológica y social; y, como se ha visto con el ejemplo del empalado, convergen en el imaginario de corrupción que se construye en el discurso novelístico de esta obra de Gamboa.
Plano fisiológico del imagina- rio de corrupción. La dimensión fisiológica de los imaginarios de corrupción, está vinculada con las transformaciones de los cuerpos y de las situacio- nes en que estos se encuentran; estos procesos corresponden a las reacciones físico-quími- cas y orgánicas, igual que a los

\footnotetext{
$5 \quad$ Esto se confirma además con el enunciado: "El pánico comenzó cuando Alberto, ¿sabes?, Cassiani, el director, se dio cuenta de que los terrenos de Pereira Antúnez que teníamos en concesión iban a ir a parar a manos del distrito si él moría, porque no había herederos. Cuando averiguamos, Esquilache nos dijo que era complicado, que esas tierras estaban contempladas dentro de una nueva delimitación y que no iba a ser fácil quedarse con ellas" (Gamboa, 2003, p. 154).

$6 \quad$ Las cursivas son nuestras.
} 
cambios que se producen por la combinación de modificaciones en la materia y la energía. ${ }^{7}$ De tal manera, en la construcción de los enunciados se construyen imágenes que se vinculan con la descomposición corporal y la autolisis ${ }^{8}$, con figuras que expresan las transformaciones de los organismos vegetales o animales, de los entornos ambientales, la aparición de olores putrefactos o la ocurrencia de condiciones de descomposición, producción de detritus y el deterioro físico en que están involucrados los personajes. La novela de Gamboa inicia con el encuentro, las descripciones y las imágenes sobre el empalado, pasaje en que se explicitan con detalle la putrefacción del cadáver, las evidencias de la tortura a la que fue sometida la víctima y los malos olores que esta descomposición produce. Como se ilustra en las siguientes descripciones del empalado: "Allá abajo huele peor que pedo de borracho. [...] El cuerpo estaba amoratado, hinchado y lleno de tierra seca. Las estacas lo atravesaban en cruz [...] Tenía marcas en las muñecas y el cuello. Lo habían amarrado y, seguro, tironeado. El agente le alcanzó una escalera de pintor y, muerto de asco, se acercó a la cara" (Gamboa, 2003, p. 10).
Las emanaciones odoríficas resultantes de la descomposición o de las eyecciones, con efectos disfóricos, también se encuentran relacionadas con espacios específicos que, en el orden del relato, aparecen como los "ahí" de la corrupción, como el bar Lolita: "El lugar olía a orines de gato" (Gamboa, 2003, p. 28). El dueño de este bar y prostíbulo es Heliodoro Tiflis, quien extorsionó a Pereira Antúnez para obtener las escrituras de los terrenos de Sisga; de este modo, las figuras que se relacionan con Tiflis están constituidas con las referencias a la descomposición orgánica. Otros ejemplos de esta corrupción fisiológica son las enfermedades, como la obesidad, producto de los excesos alimenticios del capitán Aristófanes Moya: "Sus facciones estaban marcadas por el exceso de comida y la falta de sueño: ojos inyectados, oscuras bolsas debajo de los párpados, sudoración intensa" (Gamboa, 2003, p. 18).

Plano psicológico del imaginario de corrupción. El imaginario de corrupción psicológica se vincula a los desórdenes mentales, específicamente a las actuaciones y los comportamientos erráticos y compulsivos que son indicios del desequilibrio anímico y del aparato cognitivo de las personas. José A. Carpio
(2013) propone que los actos de corrupción se producen por la combinación de un entorno propicio, una oportunidad y un tipo de personalidad que antepone, obcecadamente, el beneficio individual al interés de los demás y al cumplimiento de la ley. En la obra de Gamboa, el nivel psicológico del imaginario de corrupción está relacionado con la locura y el comportamiento compulsivo en el ámbito laboral o vinculado a los desórdenes alimenticios. En concreto, esto se comprueba con la conducta compulsiva, el alcoholismo y la adicción de Fernando Guzmán, el editor del Observador. Los expertos José Tenorio Iglesias y Juan A. Marcos Sierra (2000) explicitan que este fenómeno consiste en una patología dual, ubicada en un terreno que abarca las drogodependencias y los trastornos mentales. La compulsión del editor por las noticias no solo lo llevará a la locura, sino que hará que lo recluyan en una institución mental. Igualmente, lo podemos ver en los siguientes apartados: "Guzmán gesticulaba, se emocionaba con la realidad y la perseguía como a una presa. Quería anticiparla, comprenderla, casi seducirla [...] Las salidas nocturnas lo llevaron primero al alcohol $\mathrm{y}$, de ahí (eso Silanpa nunca lo supo a ciencia cierta), a las drogas... Decían que se drogaba para so-

De este modo, en este nivel encontramos las acepciones del término "corrupción" afines como: "echar a perder", "depravar", "dañar", "pudrir" u "oler mal" (Sandoval de la Maza, 1995).

8 La autolisis es el quiebre o ruptura de tejidos a raíz de los compuestos químicos del cuerpo y la putrefacción, la desintegración de tejidos por el accionar bacterial (Cheville, 1994). 
portar el trabajo, para estar lúcido y despierto todo el día y toda la noche" (Gamboa, 2003, p. 26).

De la misma manera, dentro de otro estamento de poder, ya no mediático sino policial, y ya no persiguiendo ni indagando por la verdad de los hechos que pueden ser noticia, sino por los delitos y los criminales, se da el caso de la obesidad y la gula del Capitán Moya, que se explican por la oscilación del sujeto entre la frustración (soledad somatizada en apetito excesivo por lo otro) y la satisfacción que brinda la comida para llenar las carencias que se revierten en los estados de ánimo: "Mi infancia se movió entre dos polos: de un lado la soledad y el hambre, del otro la felicidad y la comida" (Gamboa, 2003, p. 52). Otro ejemplo de esto es: "Comer o no comer, ¿quién decide? La cosa se puso grave un día en que, además de las tres comidas reglamentarias, me manduqué la medio pendejadita, con perdón de las señoras, de 17 chocolatinas Jet, 14 talegos de Chitos y 11 Chocorramos. Y eso sólo en lo dulce, porque en lo salado también hice plusmarca: 9 empanadas, 6 arepas con ají y 4 hamburguesas" (Gamboa, 2003, p. 33). Estas patolo- gías psicológicas se sitúan entre las sensaciones y percepciones del nivel fisiológico y el nivel social, en el que no solo se evidencian comportamientos compulsivos y obsesivos, sino que se actúa en contra del otro o se presiona al otro actuar.

El plano social del imaginario de corrupción. Este plano alude a esos modos en que se produce la descomposición de los parámetros o acuerdos de la relación intersubjetiva por causa de las acciones de alguno de los actores. Los actos ilícitos, ligados a la corrupción son la concusión, el cohecho, el peculado, el tráfico de influencias y el prevaricato. En términos de imaginarios, aquí convergen representaciones sociales que dan por hecho que todo el universo sociolectal de políticos y servidores públicos es corrupto, lo que se sostiene en la cantidad creciente de escándalos de diversa naturaleza, incluso en empresas privadas, que a diario se exponen en los medios de comunicación social. Así, este imaginario de corrupción se encuentra estrechamente vinculado a la manipulación en los procesos discursivos, precisamente donde suceden las interacciones sociales. En el caso de la novela de Gamboa, existe una serie de evidencias de la manipulación por tentación, seducción e intimidación entre tres actores colectivos o grupos de crimen organizado, o delincuencia organizada.

El texto Crimen.org, de De la Corte Ibáñez y Giménes-Salinas Framis (2010), aclara que una organización criminal es un conjunto de individuos que asumen una variedad de funciones para operar de forma coordinada y conforme a ciertas reglas, con cierta continuidad temporal; en ella, los asociados buscan acumular bienes económicos logrados por medios dominantemente ilegales. En la novela que se analiza, los delitos sobre los que predica el relato son los que se dan entre las bandas delincuenciales y los funcionarios públicos, que tienen como objeto la apropiación de los terrenos del empalado Casiodoro Pereira Antúnez. De una parte, el concejal Marco Tulio Esquilache está comprometido con un grupo de constructores llamado el GranCapital y ha cometido concusión ${ }^{9}$, peculado ${ }^{10}$ y tráfico de influencias, entre otros delitos que están fuertemente vinculados a la corrupción. Emilio Barragán, esposo de la sobrina de Esquilache, es uno de los colaboradores de este

9 La concusión o exacción ilegal que sucede cuando un funcionario público, abusando de su cargo, pide o acepta dinero para realizar trámites propios de sus obligaciones; en estas prácticas incurren policías, jueces y funcionarios de alcaldías (ver Sánchez Franco, 2001).

${ }^{10} \mathrm{El}$ delito de peculado por apropiación ocurre cuando el servidor público se apropia en provecho suyo o de un tercero de bienes del Estado o de empresas o instituciones en que este tenga parte o de bienes o fondos parafiscales, o de bienes de particulares cuya administración, tenencia o custodia se le haya confiado por razón o con ocasión de sus funcione (ver Abello Gual, 2010). 
en los asuntos legales. Esto se ilustra en:

Tenemos que encontrar esas tierras, Emilio. Los de Gran Capital ya tienen todo un proyecto de urbanización cerca del lago, cuarenta y cinco fincas con pista de golf, esquí náutico y un bosque de cacería. Si les fallo me quitan el apoyo en el Concejo [...] Quiero decir que una parte de los fondos de la campaña del año pasado venía de GranCapital, y que si no conseguimos los terrenos nos van a cortar las que sabemos y hacérnoslas comer en bistec (Gamboa, 2003, pp. 91, 92).

En la manera en que la novela expone el plano de la corrupción social, se pueden agregar otros delitos impulsados por la ambición y que se expresan a través de la manipulación por tentación, como evidencia el siguiente ejemplo:

-Yo quiero preguntarle, y perdóneme, cuánto voy a ganar yo con este asunto.

- Pues mira, Emilio, y no te disculpes que es normal. Nuestro proyecto es una vaina bien grande. Con todo arreglado y sobre la mesa la cosa se puede ir a unos 150 millones. ¿Te parece bien? (Gamboa, 2003, p. 182).
La segunda organización criminal está dirigida por Heliodoro Tiflis, dueño del hotel Esmeralda y el bar Lolitas, entre otras propiedades en Bogotá y el sur del país. Trabajaba para Casiodoro Pereira Antúnez, el jefe originario de la organización, a quien secuestra y presiona para que le escriture los terrenos de Bosa a cambio de haber pasado unos meses en la cárcel por los delitos que Pereira Antúnez cometió. Esta organización realiza actos de intimidación a Víctor Silanpa, debido a que las publicaciones e investigación periodística de este, sobre el empalado, los puede incriminar. Por un lado, Susan Cabiedes intenta sobornarlo, pero como no lo consigue, lo amenaza:

-No vengo a seducirlo, Víctor. Tal vez a comprarlo... Venga, hágase aquí, a mi lado, a ver cuánto aguanta...

La mujer le apuntó el arma a la cabeza, se sentó del otro lado del sofá y volvió a subirse la falda.

— Venga, quítese la bata y acérquese. Silanpa la obedeció temblando de miedo. El vértigo que le producía el cañón del arma le hizo perder la erección.

-A ver, superpipí, ¿de qué es capaz ahora? (Gamboa, 2003, pp. 115-116).

De otra parte, Heliodoro Tiflis ordena que le destruyan el carro a Silanpa, también para que deje de lado la investigación sobre el empalamiento, como le aclara al capitán Moya:

Vio los neumáticos del R6 por el piso. Luego abrió la puerta y pegó un grito: alguien había llenado el vidrio de salsa de tomate, restos de comida y botellas de cerveza. En el sillón del conductor había un bollo de caca que parecía reciente. Sobre el timón, en un pedazo de servilleta, había una nota: «Aquí estuvimos. Aquí comimos y aquí nos cagamos.» Por una rendija del capó, entreabierto, vio salir un racimo de cables. Le habían destruido el motor (Gamboa, 2003, p. 128).

En las dos citas anteriores, se evidencia lo que Mockus (citado en Garay y Salcedo, 2012) denomina corrupción violenta; esta consiste en métodos de coerción como la amenaza de muerte o la destrucción de sus propiedades (carro y el apartamento de Silanpa) que reemplazan o complementan el soborno. La tercera organización delictiva implicada en los crímenes contra Casiodoro Pereira Antúnez y Ósler Estupiñán, está también relacionada con la construcción, uno de los socios visibles es Ángel Vargas Vicuña. Vargas Vicuña intenta sobornar a Heliodoro Tiflis: 
- Me interesan esas tierras para construir un complejo de recreo. Usted sabe, un conjunto de casas de campo para fines de semana, un lugar para gente de recursos [...] Yo estoy dispuesto a hacer rodar un chequecito de varios ceros a la mano amiga que me traiga esos papeles, don Heliodoro. ¿Estoy siendo claro? (Gamboa, 2003, p. 136).

Luego de que le roban las escrituras originales de los Terrenos de Bosa, Heliodoro Tiflis ordena a sus empleados intimidar al periodista Silanpa, al concejal Esquilache y al contratista Vargas Vicuña. Esto se ilustra en la conversación entre Runcho y Tiflis: "—_Pegarle un susto o mandarlo al trapero? [...] Usted sabe que a mí me gusta siempre matar dos pájaros de un tiro. Hay que hacer algo que le meta miedo a Esquilache, a Vargas Vicuña, a todos" (Gamboa, 2003, p. 139). Con este y otros hechos, se constata la presencia, en la novela, de un conjunto de imágenes en las que la corrupción de las relaciones intersubjetivas es un elemento axiológico transversal. Para Orlando Mejía Rivera (Gómez, 2011), refiriéndose a Colombia, el fenómeno de la corrupción es uno de los valores que parecen connaturales en la sociedad, pues desde la colonia se han montado estructuras corruptas que, aunque han mutado, forman parte de la vida comunitaria. Para el autor, esta es una constante que se da al violar las leyes; el legalismo (o santanderismo ${ }^{11}$ ) al extremo llegó incluso a crear leyes para burlar leyes. Los comportamientos de corrupción atraviesan todos los estratos sociales y, en Perder es cuestión de méto$d o$, tiene muchas aristas, como el caso del concejal Esquilache que devuelve el favor al GranCapital, porque este invirtió en la campaña del primero.

En este caso, se debe añadir que se trata de una corrupción sistémica que Garay y Salcedo-Albarracín (2012, p. 32) explican como la captura del Estado o la intervención de individuos, grupos o compañías legales en leyes, decretos, regulaciones y políticas públicas para obtener beneficios en detrimento del interés general. De modo similar, esto se observa en los enunciados como:

Yo necesito las escrituras para adjudicárselas a ellos a precio de subasta, ¿me entiendes la mano? Para eso lo único que hay que hacer es un llamado a venta pública con la fecha de convocación cambiada. Así les devuelvo el favor $\mathrm{y}$, de paso, parte de la platica que ya me adelantaron (Gamboa, 2003, p. 182).

Igualmente, Mejía Rivera (Gómez, 2011), apoyándose en el texto La ética protestante y el espíritu del capitalismo, de Max Weber, plantea que la clase adinerada de los países influidos por el protestantismo hicieron sus fortunas honestamente, pues creían que el trabajo honorable era una forma de alabar a dios, mientras que, para los católicos, ser rico implicaba un privilegio que provenía de la providencia y, por exclusión, el trabajo era para los pobres. En suma, los países colonizados heredaron una mentalidad relacionada con el deseo de obtener dinero de manera fácil o dependiente de la autoridad. Esto se traduce en que cuando desaparecen los privilegios otorgados por el rey, o cuando no son producto de la herencia, fácilmente se tiende a adquirir la riqueza de un modo poco honesto. En Perder es cuestión de método, Víctor Silanpa averigua, apoyado por Guzmán y Estupiñán, sobre cómo están conformadaslas organizaciones delincuenciales, los delitos de toda índole vinculados con crimen del empalado y sobre las formas de operar y de reconfigurarse de las mafias. Lo observamos en ejemplos como:

\footnotetext{
${ }^{11}$ Es la recurrencia al seguimiento y la aplicación estricta de las normas legales como instrumento político para contrarrestar el poder del adversario, práctica sugerida por Francisco de Paula Santander en los inicios de la República (Ghotme Ghotme, 20017).
} 
¿Qué tal si al gordo no lo clavaron los naturistas? ¿Qué tal si más bien el gordo es una amenaza contra ellos? [...] El gordo es sólo un cuerpo. Una imagen horrible que alguien debía ver $[\ldots]$ Los terrenos son de Tiflis y los usan los naturistas. Eso está claro (Gamboa, 2003, pp. 154, 155).

En las situaciones narradas en la novela, también se observa la corrupción armada. Aunque no se trata de grupos paramilitares o de guerrilleros, se debe recordar que el surgimiento de las autodefensas en Colombia se vincula con la organización de grupos armados que defienden territorio, riquezas ilegales o la explotación de tierras fuera de la ley, lo que configura mafias, sea de narcotraficantes, de esmeralderos, de la gasolina o del contrabando: "-Creo que este fólder explica quién es el muerto y por qué lo mataron. Estupiñán leyó la carpeta [...] Los esmeralderos también son mafia, jefe, aunque hoy ya nadie se acuerde" (Gamboa, 2003, p. 170). En este ámbito de corrupción violenta, se evidencia el cambio de los modus operandi de las organizaciones delictivas colombianas representadas en el universo de ficción de la novela (en este caso, de la mafia de esmeralderos e inmobiliaria):
- Se parece a los casos de mafia de hace quince años. Hoy la vaina es con bombas y con disparos en la nuca. Qué tiempos.

— ¿Antes era así?

- Sí, nadie se atrevía a matar como no fuera por algo grave. Hoy la vida ya no tiene ningún valor.

- O sea que esto pudo haberlo hecho alguien de esa época (Gamboa, 2003, pp. 198-199).

\section{Conclusiones}

Los planos del imaginario de corrupción desglosados son interdependientes, se complemen$\tan \mathrm{y}$, en algunos casos, son el soporte de los otros. En general, no solo están vinculados entre sí, sino que en muchos de los casos son causa de la somatización de la corrupción social en el malestar psicológicos y fisiológico, como si el impacto en el orden del deber del sujeto afectara un sistema orgánico que implica la supervivencia corporal y mental, de tal suerte que lo nefasto del orden social determina, a la manera del rabo de cerdo al final de Cien años de soledad, una degeneración genética. La transformación del corrupto, que va del ser honesto a no ser honesto y legal (en el ámbito de las relaciones intersubjetivas o de la conciencia del yo sobre sí mismo) se manifiesta en el plano fisiológico con la putrefacción, el mal olor y la fealdad que aluden a imágenes como la descomposición de cadáveres, las deposiciones orgánicas, la entropía en la que entra el cuerpo vivo que se percibe en los síntomas de las enfermedades físicas o mentales. En cada uno de los casos expuestos aquí, se encuentra un vínculo entre la imagen y los imaginarios de corrupción con la sensorialidad del sujeto que la practica o que la padece como víctima.

Las operaciones de puesta en discurso de la corrupción se plantean en la convergencia de tres niveles de imágenes de ámbitos propios de la vida humana (de orden biopsicosocial). Esto permite postular la definición, como se ha hecho, de los tres planos convergentes de la corrupción. Esta se ha venido desterritorializando de los campos de las ciencias naturales y ha pasado a las ciencias sociales, quizás de la física a la semiología médica, y de esta a la psicología, la sociología y la política, en especial a la administración pública, para plantear problemas humanos $\mathrm{y}$, especialmente, los reductos de la mediocridad y de la vulnerabilidad de la vida comunitaria. Precisamente, la noción del imaginario de corrupción aparece como una dinámica dominante, vinculada a la administración pública y los estamentos políticos, desde donde se ha venido legitimando, según la predicación de la obra analizada. A la par, esta noción está ligada a la historia y cultura, a tal punto que se hace inherente a estas y gesta los conflictos armados, y a las problemáticas de crimen organizado como las del narcotráfico. 


\section{la palabra}

\section{Referencias}

Abello Gual, J. A. (2010). El abuso de confianza y el peculado en la responsabilidad penal empresarial. Revista Prolegómenos, Derechos y Valores, 13(26), 267-284. Recuperado el 07 de octubre de 2015, de https://dialnet.unirioja.es/descarga/articulo/3698880.pdf

Abbagnano, N. (1997). Diccionario de Filosofía. México: FCE.

Aristóteles. (1995). Física. Planeta de Agustini.

Caracol T.V.(Caracol Televisión). (27 de noviembre 2016). Programa Séptimo Día, Especial Colombia Corrupta, primera emisión, Bogotá [Video postcast]. Recuperado de https://www.youtube.com/ watch? $=$ hkaZCEWBsnM\&t=173s

Caracol T.V. (Caracol Televisión). (2011). Informativo el Radar. El origen de la corrupción, Gómez, B. entrevista a Orlando Mejía Rivera. Recuperado el 2 de mayo de 2012, de[http://www.noticiascaracol.com/informativos/elradar/video-244585-el-origen-de-la-corrupcion-colombia?pid=0

Carpio, J. Á. (2013). Cómo funciona la mente de un corrupto: cuando los incentivos de lucro valen más que la ética. Recuperado el 5 de marzo de 2014, de http://www.rtve.es/noticias/20130915/como-funciona-mente corrupto/746221.shtml

Courtés, J. (1997). Análisis semiótico del discurso. Madrid: Gredos.

Cheville, N. (1994). Introducción a la Patología General Veterinaria. Zaragoza: Ed. Acrib. Recuperado el 20 marzo de 2016, de https://es.scribd.com/doc/79154544/AUTOLISIS

De la Corte, L., \& Giménez Salinas, A. (2010). Crimen.org: Evolución y claves de la delincuencia organizada. Barcelona: Ariel.

Deneault, A. (2015). La mediocridad. París: Luz.

Eco, U. (1981). Lector in fabula. Barcelona: Lumen.

Fajardo, L. E. (2002). La corrupción heredada: pasado colonial, sistema legal y desarrollo económico en Colombia. Revista de Estudios Sociales, (12), 22-30. Recuperado el 24 de abril de 2015 de https://revistas.uniandes.edu.co/doi/pdf/10.7440/res12.2002.02

Franco, J. (2001). Paraíso Travel. Bogotá: Editorial Planeta.

Gamboa, S. (2003). Perder es cuestión de método. Bogotá: Planeta.

Garay, L. J., \& Salcedo-Albarán, E. (2012). Narcotráfico, corrupción y estados. Bogotá: Random House Monddori. 
Greimas, A. J., \& Courtes, J. (1995). Semiótica: Diccionario razonado de la teoría del lenguaje. Madrid: Gredos.

Ghotme, R. A. (2007). Santanderismo, antisantanderismo y la Academia Colombiana de Historia: la operación histórica en el proceso de construcción de nación en Colombia, 1910-1970. Anuario Colombiano de Historia Social y de la Cultura, (34), 121-164. Recuperado el 2 de marzo de 2016, de http://www.redalyc.org/articulo.oa?id=127112570005

Iglesias, J. T., \& ierra, M. (2000). Trastornos duales: Tratamiento y coordinación. Revista Papeles del Psicólogo, (77). Recuperado el 12 de septiembre 2014 de http://www.papelesdelpsicologo.es/ resumen?pii $=846$

Landowski, E. (2013). ¿A qué se refiere la palabra «imaginario»? Contratexto, (21,) 83-107. Recuperado el 6 de octubre de 2013, dehttp://www3.ulima.edu.pe/Revistas/contratexto/v21/05\%20-\%20 21.pdf

Mendoza, M. (2002). Satanás, Bogotá: Planeta-Colombia.

Moreno, A. (2014). Evolución del delito de cohecho y su aplicación por parte de los tribunales (Tesis). Universidad Pontificia de Comillas, Madrid, España.

Osorio, J. J. (2011). “Perder es cuestión de método: adaptación cinematográfica y cine negro”. Ponencia presentada en XVII Congreso de la Asociación Colombianistas, Narrar Colombia, Colombia narrada, Bucaramanga. Recuperado el 22 de septiembre de 2017, de http://www.colombianistas.org/portals/0/congresos/documentos/congresoxvii/osorio_jose_jesus.pdf

Panier, L. (2003). Análisis semiótico de un texto. Ficha técnica. Recuperado el 28 de marzo de 2010, de http://lesla.univlyon2.fr/sites/lesla/IMG/pdf/doc-226.pdf

Piedrahita, R. (2012). El delito de tráfico de influencias en la jurisprudencia de la Corte Suprema de Justicia. Medellín: Universidad EAFIT.

Pöppel, H. (2001). La novela policiaca en Colombia. Medellín: Editorial UDEA.

Restrepo, E. A. (2015). Colombia: en busca de su propia novela negra. Revista Solo novela negra. Recuperado el 5 de julio de 2016, de http://solonovelanegra.com/colombia-en-busca-de-su-propia-novela-negra/

Sánchez, A. (2001). El delito de la concusión cobro ilegal de impuestos. Puebla, México: O. G. S. Editores.

Sandoval, S. (1995). Diccionario etimológico de la lengua castellana. Madrid: M.E. Editores. 
Secretaría de Salud de México. (2010). Boletín de Epidemiología, 27(43). Recuperado el 2 julio de 2016, de http://www.epidemiologia.salud.gob.mx/doctos/boletin/2010/sem43.pdf

Serrano, E. (2003). El concepto de competencia en la semiótica discursiva. Bogotá: UNAL.

Solano Cohen, V. (2015). Por nosología de la violencia del narcotráfico: topos literarios de los años de la peste. La Palabra, (27), 79-92.

Stevenson, R. L. El extraño caso del Dr. Jekyll y el Sr. Hyde. Recuperado el 11 de julio de 2012, de: http://www.planetpdf.com/ 